\title{
Assessment of the short-term functional outcome after urethroplasty: a prospective analysis
}

\author{
Lumen N, Spiers S, De Backer S, Pieters R, Oosterlinck W \\ Dept. of Urology (NL, PR, WO), Ghent University Hospital, Ghent and University of Ghent (SS, \\ $S D B)$, Faculty of Medicine and Health Sciences, Ghent, Belgium
}

\begin{abstract}
Objectives: To assess the short-term functional outcomes on urinary symptoms, erectile function, urinary continence and patient's satisfaction after urethroplasty.

Materials and Methods: A prospective analysis was done in 21 patients who underwent urethroplasty. An assessment of the urinary flow, urinary symptoms (International Prostate Symptome Score $<$ IPSS $>$ ), erectile function (International Index of Erectile Function-5 <IIEF-5>) and urinary continence (International Consultation Committee on Incontinence Questionaire male Short Form $<\mathrm{ICI}-\mathrm{Q}-\mathrm{SF}>$ ) was done before urethroplasty and 6 weeks and 6 months after urethroplasty. Patients were also asked to score their satisfaction with the urethroplasty after 6 weeks and 6 months.

Results: Mean patient's age was 48 years (range: 26-80 years). Mean stricture length was $4.2 \mathrm{~cm}$ (range: $1-12 \mathrm{~cm}$ ). Three patients suffered a stricture recurrence. Mean maximum urinary flow increased from $5.83 \mathrm{~mL} / \mathrm{s}$ to $24.92 \mathrm{~mL} / \mathrm{s}$ $(\mathrm{p}<0.001)$. Mean IPSS preoperative, 6 weeks and 6 months postoperative was respectively 15.86, 4.60 and $6.41(\mathrm{p}<$ 0.001). The mean IIEF-5 score preoperative, 6 weeks and 6 months postoperative was respectively $15,12.13$ and 11.62 (not significant). The mean ICI-Q-SF score preoperative, 6 weeks and 6 months postoperative was respectively 10.47, $8.33(\mathrm{p}=0.04)$ and $9.47(\mathrm{p}=0.31)$. Patient's satisfaction 6 weeks and 6 months postoperative was respectively $17.14 / 20$ and $17.12 / 20$.

Conclusions: Urethroplasty leads to a significant improvement in urinary flow and IPSS and urinary continence is tending to improve. Although not significant, erectile function was slightly diminished after urethroplasty. Functional outcome should be assessed when urethroplasty is performed.
\end{abstract}

Key words: urethral stricture; erectile dysfunction; urinary incontinence; urethra; treatment outcome Int Braz J Urol. 2011; 37: 712-718

\section{INTRODUCTION}

Urethral stricture disease causes obstructive and irritative voiding symptoms that might have an impact on the patient's quality of life. The different techniques of urethroplasty in the treatment of urethral stricture disease are well described (1-3). Although international accepted guidelines about the treatment are lacking, some recommendations have been made (4-6). The primary outcome parameter of papers assessing the different techniques of urethroplasty has been stricture recurrence. The need for further instrumentation or reoperation is considered a stricture recurrence by the majority of urologists (7). Since urethroplasty is performed on the penis and/or in the perineum, it might have an impact on the patient's erectile function (8). Postoperative sequestration of urine in the urethra and diminished tone of the perineal muscles can lead to (an increase of) postvoid dribbling (8). Posterior urethroplasty is considered to jeopardize the function of the external urethral sphincter and might lead to urinary incontinence. All these possible alterations in urinary and sexual function might have an impact on the patient's satisfaction with the procedure. It has previously been reported that patient's satisfaction is not 
always the same as what the surgeon defines as success (9). This study mainly focusses on the impact of urethroplasty on the patient's short-term functional outcome and the satisfaction with the procedure.

\section{MATERIAL AND METHODS}

A prospective analysis on the functional outcome of urethroplasty was started in June 2008 and patient recruitment was stopped in December 2008. Only Dutch-speaking patients with a urethral stricture treated with urethroplasty and who approved the informed consent document were included. Non-Dutch speaking patients, transsexual patients, patients not giving their consent to the study and patients who were lost to follow-up were excluded.

Preoperative evaluation included history taking, physical examination, uroflowmetry, echographic residual urine measurement and urethrography. Our in-home treatment algorithm of urethroplasty has been recently described (10) and the operations were done by the same surgical team (W.O. and N.L.). The urinary catheter was removed after 2 weeks when a voiding cysto-urethrography showed absence of urinary extravasation. Follow-up in this study was done after 6 weeks and 6 months with history taking, physical examination and uroflowmetry. In case of clinical symptoms and/or a maximum urinary flow $\left(\mathrm{Q}_{\max }\right)<15 \mathrm{~mL} / \mathrm{s}$ a urethrography was performed. After closure of the study, the patients were further followed on a regular base. Stricture recurrence was defined as the need for any further instrumentation or reoperation. The functional outcome on urinary and sexual function was assessed using validated questionnaires that were offered to the patient before operation and at the 6 weeks and 6 months follow-up visits. These questionnaires are:

-The International Prostate Symptom Score (IPSS) assessing the patient's voiding symptoms. This score is mainly used for the evaluation of symptoms in patients with benign prostatic hyperplasia (BPH). Seven questions are asked with 6 possible answers leading to a score from 0 (no symptoms) to 35 (very severe symptoms).

-The International Index of Erectile Function-5 (IIEF-5) assessing the patient's erectile function. Five questions are asked with 5 possible answers leading to a score from 5 (severe erectile dysfunction) to 25 (normal erectile function). Only patients that were sexually active were asked to complete this questionnaire.

-The International Consultation Committee on Incontinence Questionnaire male Short Form (ICI-Q-SF) assessing the patient's urinary continence. Six questions are asked about urgency, urge incontinence, stress incontinence, no awareness of urine loss, nocturnal incontinence and post-void dribbling with 5 possible answers leading to a score from 5 (no symptoms) to 30 (severe urinary incontinence).

During the 6 week and 6 month follow-up visit the patients were also asked to score their satisfaction with the urethroplasty from 0 (very dissatisfied) to 20 (very satisfatied).

Twenty-one patients were recruited for the study. Mean patient's age was 48 years (range: 2680 years). Mean stricture length was $4.2 \mathrm{~cm}$ (range: 1-12 cm). Stricture etiology was idiopathic, iatrogenic, post-infectious and lichen sclerosus in respectively 9, 7, 1 and 1 patient. Three patients underwent urethroplasty for a pelvic fracture related posterior urethral distraction defect. Previous interventions were intermittent dilations, one or more internal urethrotomies, urethroplasty, a combination of internal urethrotomy with urethroplasty and none in respectively $1,5,1,4$ and 10 patients. The technique used for urethral reconstruction was anastomotic repair, free-graft urethroplasty, combined urethroplasty and perineostomy in respectively $8,10,2$ and 1 patient.

The preoperative scores of uroflowmetry, IPSS, IIEF-5 and ICI-Q-SF were compared with the scores after 6 weeks and 6 months. Statistical analysis was done using the Student t-test with PASW Statistics $^{\mathrm{TM}}$. A p-value $<0.05$ was considered statistically significant.

The study was approved by the local ethics committee (EC/UZG/2008/234).

\section{RESULTS}

Three patients suffered a recurrence: one patient during the study at 4 months and two patients at 11 and 13 months, thus after closure of study recruitement. 
The preoperative mean $\mathrm{Q}_{\max }$ was $5.83 \mathrm{~mL} / \mathrm{s}$ (range: $0-13 \mathrm{~mL} / \mathrm{s}$ ) and raised to $24.92 \mathrm{~mL} / \mathrm{s}$ (range: $7-61.9 \mathrm{~mL} / \mathrm{s}) 6 \mathrm{months}$ postoperative. This amelioration was statistically significant $(\mathrm{p}<0.001)$. In the successful cases, the mean 6 months postoperative $\mathrm{Q}_{\max }$ was $26.9 \mathrm{~mL} / \mathrm{s}$ vs $10.9 \mathrm{~mL} / \mathrm{s}$ in failures $(\mathrm{p}=$ $0.03)$.

The mean IPSS preoperative, 6 weeks and 6 months postoperative were respectively $15.96,4.60$ and 6.41. The scores after 6 weeks and 6 months were significantly better compared to the preoperative score. The raise in IPSS (thus a worsening) 6 weeks versus 6 months postoperative was not significant (Table-1). Comparing the 3 patients with
In $50 \%$ of patients undergoing anastomotic repair and $40 \%$ of patients undergoing free graft urethroplasty the IIEF-5 scores were worse 6 weeks and 6 months postoperative compared to the preoperative scores.

The most frequent reported preoperative complaint was urgency. Eighteen $(86 \%)$ patients reported urgency: 11 occasional, 4 regular, 2 most of the time and 1 always. Another important preoperative complaint was postvoid dribbling which was present in 17 (81\%) patients: 10 (48\%), 5 (24\%) and $2(9 \%)$ patients reported respectively occasional, frequent and always postvoid dribbling.

The mean ICI-Q-SF score preoperative was 10.48. This score declined (thus an amelioration) to

Table 1 - Results IPSS.

\section{IPSS}

Preoperative

6 weeks postoperative

6 months postoperative

\section{IPSS}

Preoperative versus 6 weeks postoperative

Preoperative versus 6 months postoperative

6 weeks versus 6 months postoperative
Mean (95\% Confidential Interval)

$15.86(11.86-19.85)$

$4.60(2.00-7.20)$

$6.41(3.29-9.53)$

Mean Difference (95\% Confidential Interval)

$10.40(6.13-14.67)$

P-value

$9.00(5.17-12.84)$

$<0.001$

$<0.001$

$-1.00(-2.53-0.53)$

0.179 a recurrence versus the other patients, there was a higher 6 weeks (10.3 vs 4.07) and 6 months (13 vs 6.41) IPSS in the patients with a recurrence.

Twenty patients were sexually active and filled in the IIEF-5scores. The mean IIEF-5 scores preoperative, 6 weeks and 6 months postoperative were respectively $15,12.13$ and 11.62 . There was a mean decline (thus worsening) in IIEF-5 scores preoperative versus 6 weeks and 6 months postoperative. Comparing the scores 6 weeks versus 6 months postoperative there was a mean raise (thus amelioration) in IIEF- 5 scores of 0.75 . The mean differences in IIEF-5 scores preoperative and 6 weeks and 6 months postoperative didn't reach statistical significance (Table-2). Erectile function was the worst in the 3 patients with pelvic fracture related urethral distraction defect with a preoperative, 6 weeks and 6 months postoperative IIEF-5 score of respectively 6,5 and 7 .
8.33 and 9.47 respectively 6 weeks and 6 months postoperative. The mean difference in ICI-Q-SF score preoperative and 6 weeks postoperative even reached statistical significance (Table-3). The postoperative decline in ICI-Q-SF score was mainly due to an amelioration in urgency, urge incontinence and postvoid dribbling. Urgency dropped to $47 \%$ and $53 \%$ respectively 6 weeks and 6 months postoperative. Urge-incontinence was reported preoperatively by $43 \%$ of the patients and this also dropped to $27 \%$ and 29\% 6 weeks and 6 months postoperative. Postvoid dribbling diminished to $27 \%$ and $29 \% 6$ weeks and 6 months postoperative.

The mean scores of satisfaction with the operation were 17, 14 and 17, 12/20. After 6 weeks no one was dissatisfied (score $\leq 10$ ) but after 6 months, one patient was dissatisfied with the operation because of a post-operative fistula. 
Table 2 - Results IIEF-5 scores.

\begin{tabular}{lcc}
\hline IIEF-5 score & Mean (95\% Confidential Interval) & \\
\hline Preoperative & $15(11.55-18.45)$ & \\
6 weeks postoperative & $12.13(7.38-16.88)$ & \\
6 months postoperative & $11.62(7.62-15.63)$ & \\
IIEF-5 score & Mean difference (95\% Confidential Interval) & P-value \\
Preoperative versus 6 weeks postoperative & $-1.50(-4.51-1.51)$ & 0.30 \\
Preoperative versus 6 months postoperative & $-2.31(-5.18-0.56)$ & 0.11 \\
6 weeks versus 6 months postoperative & $0.75(-1.84-3.34)$ & 0.54 \\
\hline
\end{tabular}

Table 3 - Results ICI-Q-SF score.

\begin{tabular}{lcc}
\hline ICI-Q-SF score & Mean (95\% Confidential Interval) & \\
\hline Preoperative & $10.47(8.65-12.30)$ & \\
6 weeks postoperative & $8.33(6.90-9.76)$ & \\
6 months postoperative & $9.47(7.18-11.76)$ & \\
ICI-Q-SF score & Mean difference (95\% Confidential Interval) & P-value \\
Preoperative versus 6 weeks postoperative & $2.27(0.10-4.44)$ & 0.042 \\
Preoperative versus 6 months postoperative & $1.24(-1.28-3.75)$ & 0.313 \\
6 weeks versus 6 months postoperative & $-0.08(-1.53-1.36)$ & 0.901 \\
\hline
\end{tabular}

\section{DISCUSSION}

\section{$Q_{\max }$ and IPSS}

Reconstruction of a normal urethral diameter should lead to a normalisation of the urinary flow and a reduction of lower urinary tract symptoms. In this study, a significant amelioration of $\mathrm{Q}_{\max }$ was observed 6 months after urethroplasty. Moreover, successful cases had a significant better $\mathrm{Q}_{\max }$ compared to the failures. These findings suggest that uroflowmetry is a useful examination in the follow-up of patients after urethroplasty. A significant positive correlation between $\mathrm{Q}_{\max }$ and urethral diameter has been reported by Heyns and Marais (11). In Europe, the most frequently used questionnaire about urinary symptoms is the IPSS. The American equivalent (identical 7 questions) is the American Urological Association Symptom Score (AUA-SS). Although IPSS/AUA-SS were initially designed and validated to assess treatment for $\mathrm{BPH}$, it can be used to evalu- ate other causes of lower urinary tract obstruction. A significant inverse correlation between the urethral diameter and the AUA-SS has been reported $(11,12)$. Our study shows a significant amelioration of the postoperative IPSS score suggesting that the reconstruction of a normal urethral diameter is responsible for this. Comparing the patients with a recurrence versus the other patients, there was a higher 6 weeks and 6 months IPSS in the patients with a recurrence. This suggests that a high IPSS might be a predictor of stricture recurrence. This was also observed in other studies using the AUA-SS $(11,12)$ : a persistent high symptom score correlated well with a recurrent stricture. The drawback of the use of both maximum urinary flow and IPSS is the lack of specificity for recurrence of urethral stricture disease (13). Other factors affecting the lower urinary tract such as $\mathrm{BPH}$, dysfunctional voiding and neurogenic bladder can also explain a persistent low $\mathrm{Q}_{\max }$ and high IPSS. Nevertheless, rapid deterioration of $\mathrm{Q}_{\max }$ and IPSS, 
especially in young and otherwise healthy patients should be considered as a sign of stricture recurrence and justifies further and more invasive examinations such as urethroscopy and urethrography. It was recently reported that to detect stricture recurrence, a 2-tier approach seems to be the most frequently used (7). This strategy consists of a non-invasive screening method in the first tier, followed by more invasive tests (e.g. urethrography or urethroscopy) if the first tier is suspicious for stricture recurrence. In the first tier, questionnaires about urinary symptoms (IPSS or AUA-SS) and uroflowmetry were often used.

\section{IIEF-5}

For decades, urethral surgeons haven't paid much attention to erectile function after urethroplasty except in case of pelvic fracture related urethral injuries $(14,15)$. A possible explanation for this is that in urethroplasty the urethra and corpus spongiosum are manipulated and not the corpora cavernosa which are responsible for the erectile rigidity. During the last years, there is emerging interest about the erectile function after anterior urethroplasty. Coursey et al. were the first to ascertain the effect of anterior urethroplasty on erectile function (16): they were able to detect a significant transient decline in erectile function, but only for long urethral strictures. No validated questionnaires were used in this retrospective study. Recently, 2 prospective studies have been published using the IIEF to assess erectile function after urethroplasty. These studies of Erickson (17) (52 patients) and Xie (18) (125 patients) came to similar conclusions: about $40 \%$ reported diminished erectile function post-operatively with recovery in most patients after 6 months. These studies also showed that bulbar and especially anastomotic repair appears to have a greater effect on erectile function. Although our study was not able to show any statistical differences (probably due the limited number of patients), our findings are consistent with the 2 latter studies: a decline in erectile function after urethroplasty which was more prevalent in the group of anastomotic repair compared to free-graft urethroplasty. These alterations in sexual function may have several explanations: in deep bulbar urethroplasty, dissection in the space between the cav- ernosal bodies just under the pubic arch can damage the cavernosal nerves at the site where they perforate the urogenital diaphragm (19). Especially in anastomotic repair this dissection is done more extensively to gain urethral length in order to be able to perform a tension free anastomosis. Moreover, extensive dissection of the corpus spongiosum can lead to penile shortening and chordee certainly if done beyond the level of the penoscrotal angle. Another explanation is the disruption of the perineal nerves when splitting the bulbospongious muscle. Extensions of the perineal nerves to the frenular area are described and damage can lead to an altered sensation of this normally higly sensitive frenular area. Furthermore, intimate connections are described between the cavernosal nerves and the perineal nerves suggesting that the perineal nerves might also aid in obtaining erectile rigidity (19).

Erectile function after urethroplasty for pelvic fracture related urethral injuries was the worst, but the erectile function was already bad before operation. The pelvic trauma itself can damage the cavernosal nerves and/or to the blood supply of the corpora cavernosa (branches of the A.pudenda interna) (20). The difficult dissection at the membranous urethra during posterior urethroplasty can further damage the neurovascular structures related to the corpora cavernosa (18), although others have observed spontaneous recovery of erectile function after posterior urethroplasty $(21,22)$.

\section{ICI-Q-SF}

Urge and urge-incontinence were very frequent preoperative complaints, explained by secondary detrusor hypertrophy and instability as a consequence of chronic obstruction. These complaints were less frequent, but not absent after urethroplasty. The reason for this is that detrusor hypertrophy and instability will not directly vanish after relieve of the obstruction but will need some time to recover. Postvoid dribbling was another frequent preoperative complaint. This might be explained by difficulties of expulsing the last drops of urine because of the narrowed urethral lumen. This also strongly diminished after operation, but remained in about one fourth of the patients. Possible explanations for postoperative 
postvoid dribbling are stricture recurrence, damage to the M.bulbospongiosum and/or sacculation of the graft. In the study of Kessler et al., postoperative postvoid dribbling was even present in $58.9 \%$ of the patients (9).

\section{Patient satisfaction}

Mean patient satisfaction after urethroplasty in this series was high. The only dissatisfied patient in this series was because of a postoperative fistula. It has been reported that postoperative complications might have an influence on the patient satisfaction (9). The other 20 patients were satisfied by the operation despite some functional disturbances (erectile dysfunction, urge-incontinence, post-void dribbling). Even the patients with a recurrence were still satisfied with the operation. This again shows that patient satisfaction is not the same as what the surgeon defines as success (9).

\section{CONCLUSIONS}

Urethroplasty leads to a significant improvement in urinary flow and IPSS. Urinary continence is tending to improve, mainly due to postoperative amelioration of urge, urge-incontinence and postvoid dribbling. Although not significant, erectile function was slightly diminished after urethroplasty. Patient satisfaction after urethroplasty was high and not related to absence of recurrence. Functional outcome should be assessed after urethroplasty. Studies with more patients and a longer follow-up are needed to assess the long-term functional outcome.

\section{CONFLICT OF INTEREST}

None declared.

\section{REFERENCES}

1. Barbagli G, Lazzeri M: Surgical treatment of anterior urethral stricture diseases: brief overview. Int Braz J Urol. 2007; 33: 461-9.

2. Barbagli G, Palminteri E, Lazzeri M, Guazzoni G: Anterior urethral strictures. BJU Int. 2003; 92: 497505 .
3. Oosterlinck W, Lumen N, Van Cauwenberghe G: Surgical treatment of urethral stenoses: technical aspects. Ann Urol (Paris). 2007; 41: 173-207.

4. Andrich DE, Mundy AR: What is the best technique for urethroplasty? Eur Urol. 2008; 54: 1031-41.

5. Lumen N, Hoebeke P, Oosterlinck W: Urethroplasty for urethral strictures: quality assessment of an inhome algorithm. Int J Urol. 2010; 17: 167-74.

6. MacDonald MF, Santucci RA: Review and treatment algorithm of open surgical techniques for management of urethral strictures. Urology. 2005; 65: 9-15.

7. Meeks JJ, Erickson BA, Granieri MA, Gonzalez CM: Stricture recurrence after urethroplasty: a systematic review. J Urol. 2009; 182: 1266-70.

8. Barbagli G, De Stefani S, Annino F, De Carne C, Bianchi G: Muscle- and nerve-sparing bulbar urethroplasty: a new technique. Eur Urol. 2008; 54: 335-43.

9. Kessler TM, Fisch M, Heitz M, Olianas R, Schreiter F: Patient satisfaction with the outcome of surgery for urethral stricture. J Urol. 2002; 167: 2507-11.

10. Lumen N, Hoebeke P, Oosterlinck W: Ventral longitudinal stricturotomy and transversal closure: the Heineke-Mikulicz principle in urethroplasty. Urology. 2010; 7: 1478-82.

11. Heyns CF, Marais DC: Prospective evaluation of the American Urological Association symptom index and peak urinary flow rate for the followup of men with known urethral stricture disease. J Urol. 2002; 168: 2051-4.

12. Aydos MM, Memis A, Yakupoglu YK, Ozdal OL, Oztekin V: The use and efficacy of the American Urological Association Symptom Index in assessing the outcome of urethroplasty for post-traumatic complete posterior urethral strictures. BJU Int. 2001; 88: 382-4.

13. Stoevelaar HJ, van de Beek C, Nijs HG, Casparie AF, McDonnell J, Janknegt RA: The symptom questionnaire for benign prostatic hyperplasia: an ambiguous indicator for an ambiguous disease. Br J Urol. 1996; 77: 181-5.

14. Corriere JN Jr, Rudy DC, Benson GS: Voiding and erectile function after delayed one-stage repair of posterior urethral disruptions in 50 men with a fractured pelvis. J Trauma. 1994; 37: 587-9; discussion 589-90.

15. Pierce JM Jr: Sexual function after a urethroplasty for membranous-prostatic urethral stricture. Trans Am Assoc Genitourin Surg. 1975; 67: 77-80.

16. Coursey JW, Morey AF, McAninch JW, Summerton DJ, Secrest C, White P, et al.: Erectile function after anterior urethroplasty. J Urol. 2001; 166: 2273-6. 
17. Erickson BA, Granieri MA, Meeks JJ, Cashy JP, Gonzalez CM: Prospective analysis of erectile dysfunction after anterior urethroplasty: incidence and recovery of function. J Urol. 2010; 183: 657-61.

18. Xie H, Xu YM, Xu XL, Sa YL, Wu DL, Zhang XC: Evaluation of erectile function after urethral reconstruction: a prospective study. Asian J Androl. 2009; 11: 209-14.

19. Yucel S, Baskin LS: Identification of communicating branches among the dorsal, perineal and cavernous nerves of the penis. J Urol. 2003; 170: 153-8.
20. Shenfeld OZ, Kiselgorf D, Gofrit ON, Verstandig AG, Landau EH, Pode D, et al.: The incidence and causes of erectile dysfunction after pelvic fractures associated with posterior urethral disruption. J Urol. 2003; 169: 2173-6.

21. Lumen N, Hoebeke P, Troyer BD, Ysebaert B, Oosterlinck W: Perineal anastomotic urethroplasty for posttraumatic urethral stricture with or without previous urethral manipulations: a review of 61 cases with long-term followup. J Urol. 2009; 181: 1196-200.

22. Koraitim MM: The lessons of 145 posttraumatic posterior urethral strictures treated in 17 years. J Urol. 1995; 153: 63-6.
Submitted for publication:

January 14, 2011

\author{
Correspondence address: \\ Dr. N. Lumen \\ Dept. of Urology, \\ Ghent University Hospital, \\ De Pintelaan 185, 9000 Ghent, Belgium \\ E-mail: nicolaas.lumen@uzgent.be
}

Accepted after revision:

April 26, 2011 